\title{
High-Voltage Nanosecond Discharge as a Means of Fast Energy Switching
}

\author{
Dmitry Beloplotov *, Dmitry Sorokin (D) and Victor Tarasenko (D) \\ Institute of High Current Electronics, 634055 Tomsk, Russia; SDMa-70@loi.hcei.tsc.ru (D.S.); \\ VFT@loi.hcei.tsc.ru (V.T.) \\ * Correspondence: rff.qep.bdim@lgmail.com
}

Citation: Beloplotov, D.; Sorokin, D.; Tarasenko, V. High-Voltage Nanosecond Discharge as a Means of Fast Energy Switching. Energies 2021, 14, 8449. https://doi.org/10.3390/ en14248449

Academic Editor: Pietro Romano

Received: 19 November 2021 Accepted: 10 December 2021 Published: 14 December 2021

Publisher's Note: MDPI stays neutral with regard to jurisdictional claims in published maps and institutional affiliations.

Copyright: (C) 2021 by the authors Licensee MDPI, Basel, Switzerland. This article is an open access article distributed under the terms and conditions of the Creative Commons Attribution (CC BY) license (https:// creativecommons.org/licenses/by/ $4.0 /)$.

\begin{abstract}
The formation of a nanosecond discharge with the use of a Hamamatsu streak-camera and with simultaneously wideband $(10 \mathrm{GHz})$ measurement of voltage and displacement current caused by a streamer in one pulse has been studied. Nanosecond voltage pulses of various amplitudes (16, 20 , and $27 \mathrm{kV})$ were applied across a point-to-plane gap $(8.5 \mathrm{~mm})$ filled with air at various pressures $(13,25,50,100$, and $200 \mathrm{kPa})$. It was found that the voltage across the gap drops as soon as a streamer appears in the vicinity of the pointed electrode. At the same time, a pre-breakdown current begins to flow. The magnitude of the pre-breakdown current, as well as the voltage drop, is determined by the rate of formation of dense plasma and, accordingly, by the rate of redistribution of the electric field in the gap. The streamer velocity determines the rise time and amplitude of the current. The higher the streamer velocity, the shorter the rise time and the higher the amplitude of the pre-breakdown current. The propagation of a backward and third ionization waves was observed both with the streak camera and by measuring the displacement current. As they propagate, the discharge current increases to its amplitude value.
\end{abstract}

Keywords: nanosecond discharge; breakdown; streamer; ionization wave; dynamic displacement current

\section{Introduction}

Nanosecond discharges in gases in a sharply inhomogeneous electric fields have attracted the attention of researchers all over the world [1-10]. The reason for this is the wide range of applications for such discharges. Nanosecond discharges in a sharply inhomogeneous electric field are primarily interesting from the point of view of cold plasma generation, in which various chemically active particles are produced. Cold plasma can be used for the treatment of products, packaging products, exhaust gases and wastewater, metals, semiconductors, and dielectrics, as well as living tissues [11,12]. On the other hand, nanosecond discharges in a sharply inhomogeneous electric field are characterized by high rates of ionization processes at relatively low voltages due to the enhancement of the electric field near sharp electrodes. Potentially, they can be used as fast ( $<1 \mathrm{~ns}$ ) energy switches in the voltage range of tens of kilovolts. Due to the use of pointed electrodes, providing field emission of initial electrons [13], it is possible to achieve high stability of the operation of such a switch, and the diffuse nature of the discharge excludes the high-temperature effect of plasma.

In recent studies, it was found that the formation and propagation of streamers is accompanied by a noticeable current [14]. The magnitude of the current is proportional to the streamer velocity. Theoretical studies have shown that a voltage drop occurs even before the gap is completely bridged by the plasma, when the front of the plasma channel propagates with sub-light velocities $[15,16]$. In this regard, it becomes necessary to study the dynamics of the discharge formation with reference to the voltage and current dynamics in order to understand the relationship between the magnitude of the current, the current rise time, the voltage drop, and the dynamics of the streamer development. However, a problem arises: how to synchronize data from streak cameras with the waveforms of voltage and 
current with an accuracy of $\sim 0.1 \mathrm{~ns}$ ? For this, the measurement of a displacement current that occurs when applied voltage rises rapidly, as well as when a streamer appears and propagates, can be used $[17,18]$. The displacement current caused by the streamer is called the dynamic displacement current (DDC) $[17,18]$. By measuring DDC, the moment of appearance of the streamer and the moment of its arrival at the opposite electrode can be accurately determined.

The purpose is to find experimentally and study the relationship between the dynamics of the discharge formation and the amplitude-time characteristics of current and voltage.

\section{Experimental Setup and Methods}

The setup applied in the experiments is shown in Figure 1. A gas discharge chamber was designed for recording voltage pulse with short $(\sim 0.1 \mathrm{~ns})$ rising and falling edges. This was combined with a transmission line (wave impedance $Z$ is $75 \Omega$ ) equipped with a capacitive voltage divider (CVD). A detailed description and study of the capabilities of the measuring sensors (CVDs, current shunts, collectors) used in the setup are described in $[19,20]$.

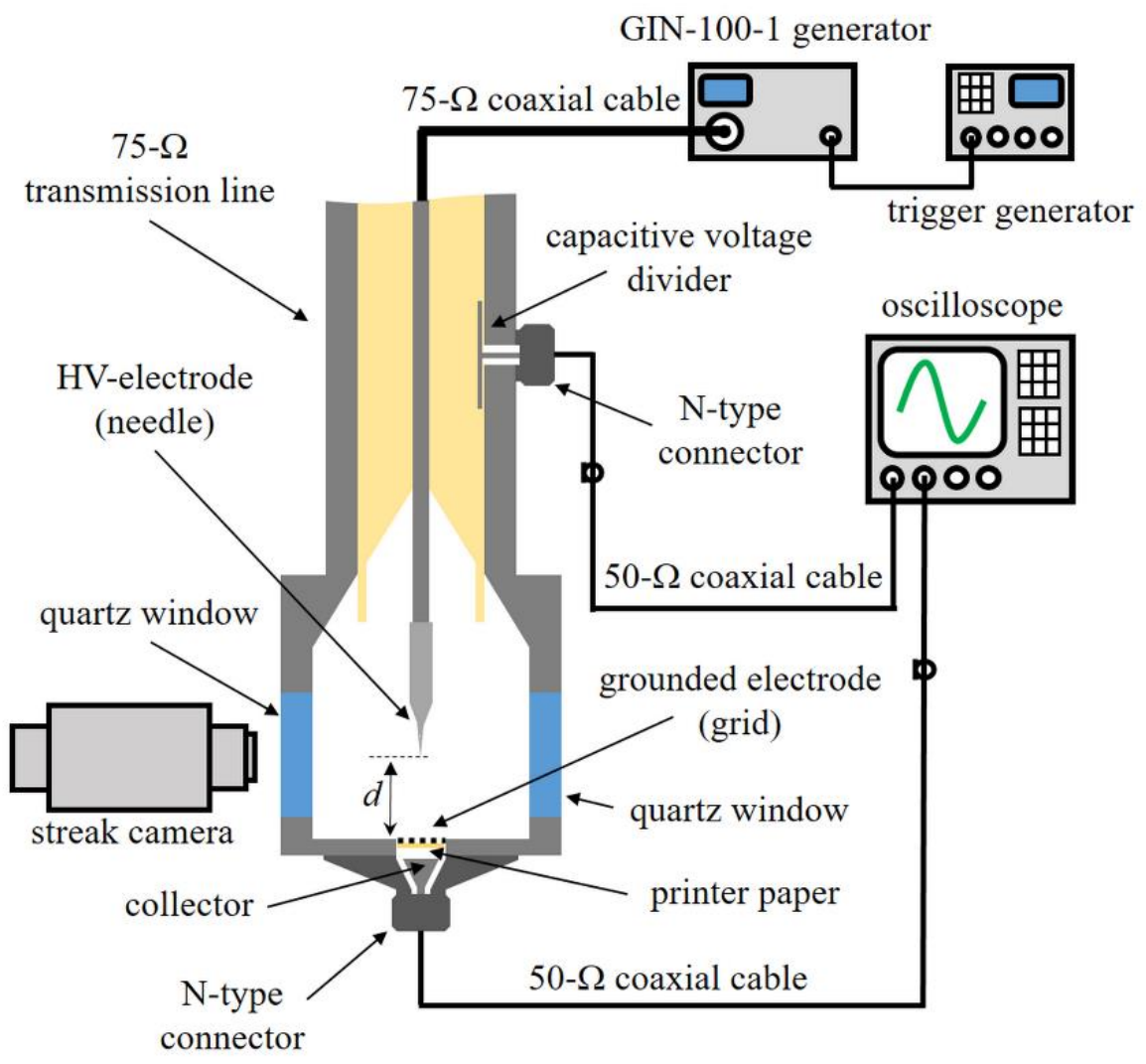

Figure 1. Experimental setup.

Nanosecond voltage pulses, $U_{0}$, of various amplitudes (Figure 2) produced by an Antares GIN-100-1 generator [21] were applied to a pointed electrode made of a piece of a sewing needle (stainless steel) $5 \mathrm{~mm}$ long via a high-voltage coaxial cable $3 \mathrm{~m}$ long. Its wave impedance was also $75 \Omega$. The needle diameter was $1 \mathrm{~mm}$, and the needle tip curvature radius was $0.075 \mathrm{~mm}$. The grounded electrode was made of a perforated grid (Figure 1). Its light transmittance was 0.75 . The distance between the pointed and grounded electrodes was $d=8.5 \mathrm{~mm}$. 


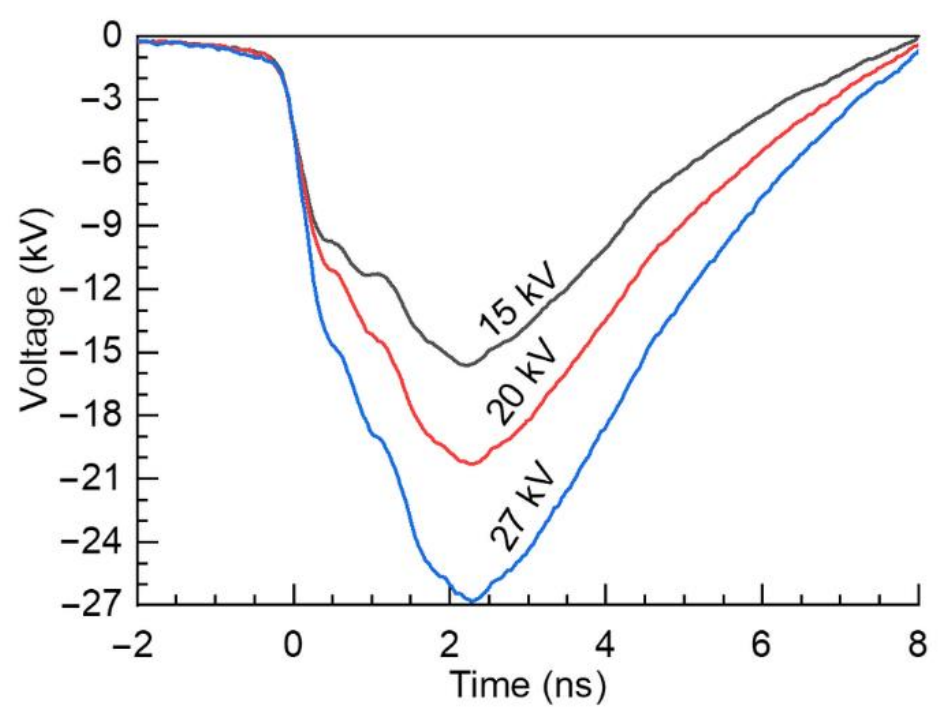

Figure 2. Voltage pulses $U_{0}$ of various amplitudes $(16,20,27 \mathrm{kV})$ produced by an Antares GIN-100-1 generator at a matched load.

A voltage across the gap, $U_{\text {gap }}$, was defined from the incident wave, $U_{0}$ (Figure 2 ), and the reflected wave, $U_{\text {ref. }}$. The incident wave was measured by applying a homemade quick-detachable transmission line $2 \mathrm{~m}$ long (wave impedance $Z$ is $75 \Omega$ ), equipped with the same CVD, in an individual series of experiments. Knowing the incident wave, $U_{0}$, we could easily calculate the reflected wave, $U_{\text {ref }}$, from $U_{\mathrm{CVD}}$ (signal from CVD).

The current of discharge, $I_{\mathrm{d}}$, can also be easily defined from the incident and reflected waves: $I_{\mathrm{d}}=\left(U_{0}-U_{\text {ref }}\right) / Z$.

DDC caused by the redistribution of the electric filed during the streamer formation was measured with a collector placed downstream of the grounded electrode. To exclude the influence of sub-nanosecond current pulses of runaway electrons (REs) generated during a pre-breakdown stage [22], printer paper with a thickness of $\approx 0.1 \mathrm{~mm}$ was placed on the back of the grounded grid close to it. The paper absorbed the REs, and they did not give a signal. The distance between the grounded grid electrode and collector was $2 \mathrm{~mm}$, and it was much greater than the thickness of the printer paper $(\approx 0.1 \mathrm{~mm})$.

The streamer formation dynamics were studied with a Hamamatsu C10910-05 streak camera. The slit of the streak camera was oriented along the gap axis from the pointed electrode tip to the surface of the grounded electrode. The slit width was $0.02 \mathrm{~mm}$, which ensured the temporal resolution in order of magnitude of tens of picoseconds. Every streak image presented below was taken per one shot. The Antares GIN-100-1 generator was operated in a single-pulse mode.

Signals from CVD and collector were fed to a Tektronix MSO64B oscilloscope $(10 \mathrm{GHz}$, $20 \mathrm{GS} / \mathrm{s}$ ) via RadioLab 5D-FB PEEG coaxial cables (50 Ohm) with bandwidth up to $30 \mathrm{GHz}$.

The discharge chamber was pumped out with a fore vacuum pump and then filled with air. The pressure was varied in the range of $13-200 \mathrm{kPa}$.

\section{Results and Discussion}

Figure 3 shows the images of the discharge plasma emission taken with an ordinary Sony A100 digital camera in one pulse. It can be seen that a diffuse discharge is formed over the entire pressure range (13-200 $\mathrm{kPa}$ ). The diameter of discharge channel increases with a decrease in pressure due to an increase in the reduced electric field strength and, as a consequence, an increase in the streamer diameter. Under experimental conditions, the photoluminescence of the paper, placed behind the grounded grid electrode to absorb REs, is observed under the action of $\mathrm{UV}$ emission from $\mathrm{N}_{2}$ molecules. 


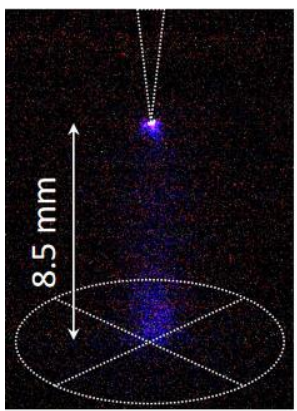

$200 \mathrm{kPa}$

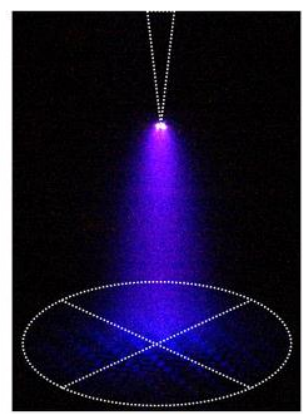

$100 \mathrm{kPa}$

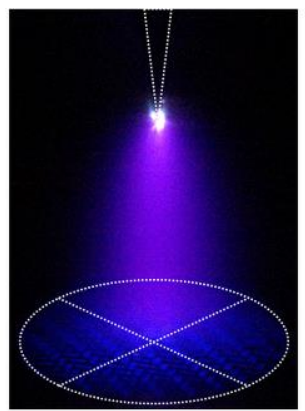

$50 \mathrm{kPa}$

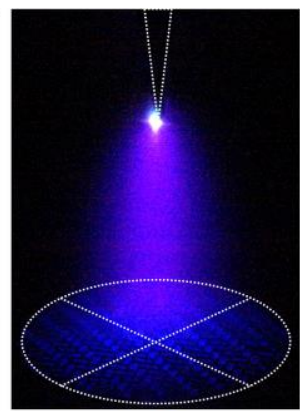

$25 \mathrm{kPa}$

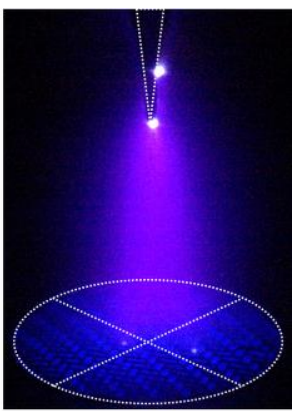

$13 \mathrm{kPa}$

Figure 3. Images of the discharge plasma emission in a point-to-plane gap filled with air at various pressures when applying voltage pulses with an amplitude of $27 \mathrm{kV}$.

Previous studies performed with a four channel ICCD camera showed that a largediameter streamer develops in the gap filled with air [14]. The streamer diameter changes during its propagation to the opposite electrode. The streamer velocity also changes following a change in the streamer diameter, because the electric field strength at the streamer front changes with a change in the radius of curvature of the streamer front surface and a decrease in the distance to the opposite electrode. However, the study of the dynamics of discharge formation using streak cameras while simultaneously measuring voltage and current as the main switching characteristics has not yet been carried out.

At the first stage of research, the experiments were carried out at an air pressure of $200 \mathrm{kPa}$. At this air pressure, the streamer propagated relatively slowly, and at the minimum amplitude of the voltage pulse, it might not have time to cross the gap. The pressure then gradually decreased and the switching rate increased. This made it possible to study the switching process in detail.

Figure 4 shows the streak-images of the discharge formation in air at a pressure of $200 \mathrm{kPa}$ and corresponding waveforms of voltage, $U_{\text {gap }}$, current, $I_{\mathrm{d}}$, displacement current measured with the collector placed downstream the grounded grid electrode, and the electric field strength (calculated) near the surface of the grounded electrode (Figure 1). Displacement current consists of $C_{\text {gap }} d U_{\text {gap }} / d t$ and the dynamic displacement current (DDC) caused by a streamer.

The use of electrodes with a small radius of curvature ensures the enhancement of the electric field near its surface up to several $\mathrm{MV} / \mathrm{cm}$ at a voltage of tens of kilovolts [22]. However, the average electric field strength can remain below the breakdown threshold. In this case, the ionization processes begin in a strong electric field, electron avalanches quickly transform into a streamer, and the plasma front moves to the region of a weak electric field.

When applying voltage pulses with the smallest amplitude (Figure 4a,d), the streamer was unable to cross the gap. The reason for this is a decrease in the electric field strength at its front with an increase in the streamer diameter [3]. Nevertheless, the appearance of the streamer causes the redistribution of the electric field strength, and DDC flows (Figure $4 \mathrm{~d}$ ). The amplitude of current through the gap reaches $\approx 10 \mathrm{~A}$. The presence of current in the external circuit causes a slight voltage drop. The collector placed downstream of the grounded grid electrode captures the change in the electric field strength caused by the streamer, and the DDC signal can be seen in Figure 4d. The polarity of DDC shows that the electric field near the grounded electrode increases as the streamer develops in the vicinity of the pointed electrode (Figure $4 \mathrm{~d}$ ), and the electric field is 'squeezed out' from there by dense plasma. The electric field strength near the surface of the grounded electrode was calculated using the DDC signal according to the method described in [22]. The appearance of DDC correlates with the moment when voltage drops and current arises and corresponds the moment of the streamer start. 

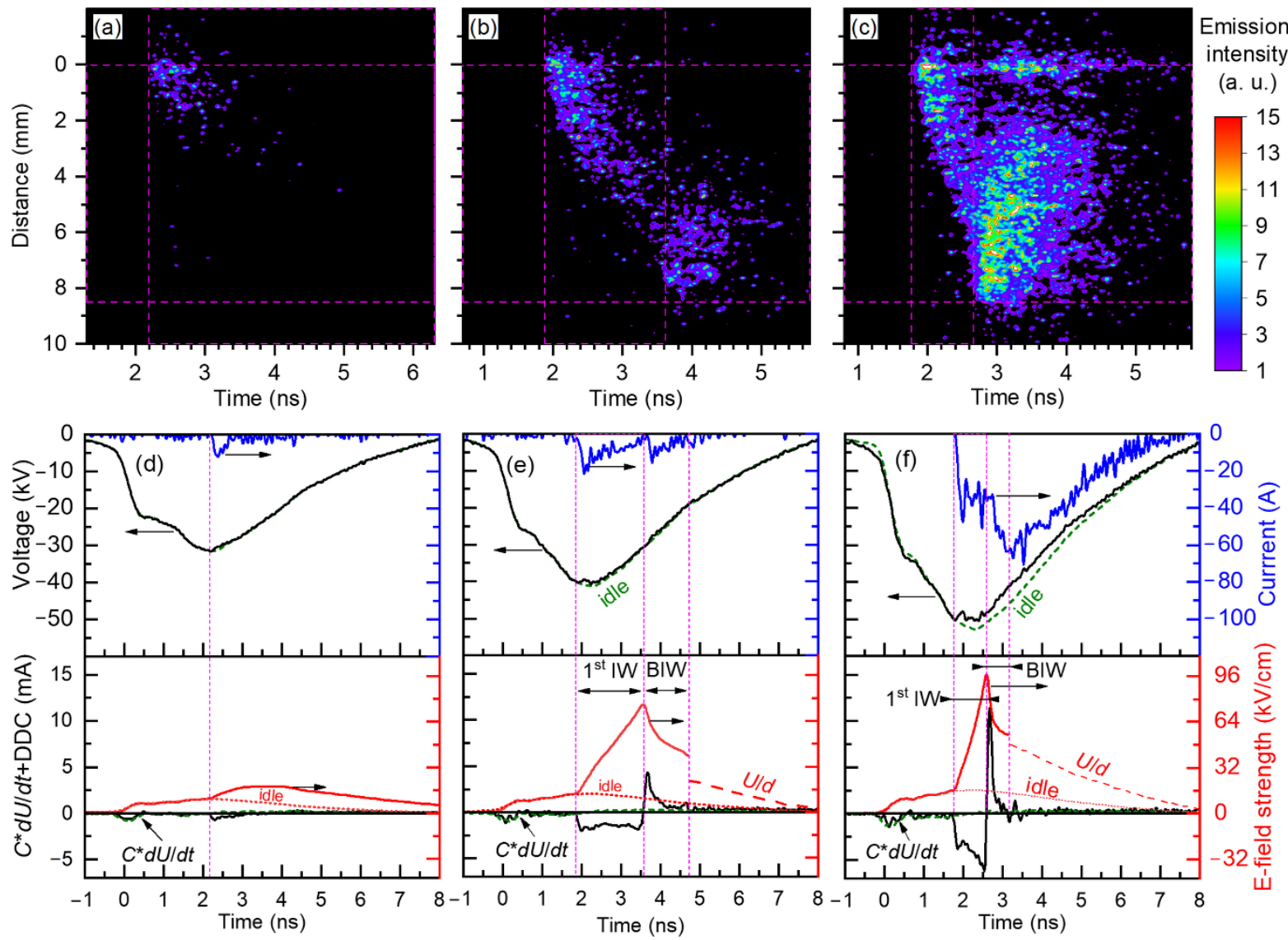

Figure 4. (a-c) Streak-images of the discharge formation dynamics and (d-f) corresponding waveforms of voltage, $U_{\text {gap }}$ current, $I_{\mathrm{d}}$, displacement current $\left(C_{\text {gap }} d U_{\text {gap }} / d t+\right.$ DDC) measured with the collector placed downstream the grounded grid electrode, and the electric field strength (calculated) near the surface of the grounded electrode at various voltages across the gap. 1st IW-first ionization wave (streamer), BIW-backward ionization wave. Air at a pressure of $200 \mathrm{kPa}$.

At a higher voltage (Figure $4 \mathrm{~b}, \mathrm{e}$ ), the streamer was able to cross the gap. The streakimage in Figure $4 \mathrm{~b}$ shows that the streamer slows down while moving towards the opposite electrode, but it still reaches the electrode surface. Waveforms (Figure 4e) show that when the streamer occurs, the current begins to flow through the gap, but its value decreases with time as the streamer slows down. At this time, DDC is measured with the collector. The DDC polarity at the stage of streamer propagation to the opposite electrode shows that the electric field strength increases near the grounded grid electrode (E-field strength in Figure 4e). However, as soon as the streamer front approaches the opposite electrode, the gas near its surface begins to rapidly ionize, and the electric field strength, consequently, decreases (the DDC polarity changes to the opposite one in Figure 4e). The electric field is redistributed along the plasma channel-the first ionization wave (streamer) flows smoothly into the backward ionization wave. At this moment, the current through the gap begins to increase again.

No qualitative changes are observed when applying voltage pulses with the highest amplitude (Figure 4c,f). However, the formation time of the streamer decreases and the pre-breakdown current increases. In this case, the streamer does not experience strong deceleration in the middle of the gap, and the value of the pre-breakdown current does not decrease. The current increases to a maximum value when the backward ionization wave propagates.

The electric field strength near the surface of the grounded electrode reaches almost $100 \mathrm{kV} / \mathrm{cm}$ when the streamer arrives there. If we take into account the fact that the distribution of the electric field strength between the grounded flat electrode and the front of the large diameter streamer [14], when it has already crossed more than half of the 
gap, is almost uniform, we can then assume that this value of the electric field strength $(100 \mathrm{kV} / \mathrm{cm})$ corresponds to the one at the streamer front. How can you determine when the field between the streamer and the flat electrode becomes uniform? We believe that the almost instantaneous gas ionization observed in the streak-image (Figure 4c) at a distance of 6-8.5 mm corresponds to the case when the field is uniformly distributed. As the gas is ionized and the concentration of charged particles grows, the electric field is 'squeezed out' from this area (redistribution occurs), and the backward ionization wave starts at a distance of $\approx 2 \mathrm{~mm}$ from the grounded electrode surface (coordinate $\approx 6 \mathrm{~mm}$ ).

Figure 5 shows the streak-images and corresponding waveforms for the discharge formation in air at a pressure of $100 \mathrm{kPa}$. The same dynamics of discharge formation with the propagation of forward and backward ionization waves is observed. However, the ionization wave velocities are higher due to the higher reduced electric field strength. An increase in the ionization wave velocities leads to an increase in the pre-breakdown current and, accordingly, to a larger voltage drop across the gap when compared with the data for a pressure of $200 \mathrm{kPa}$ (Figure 4).
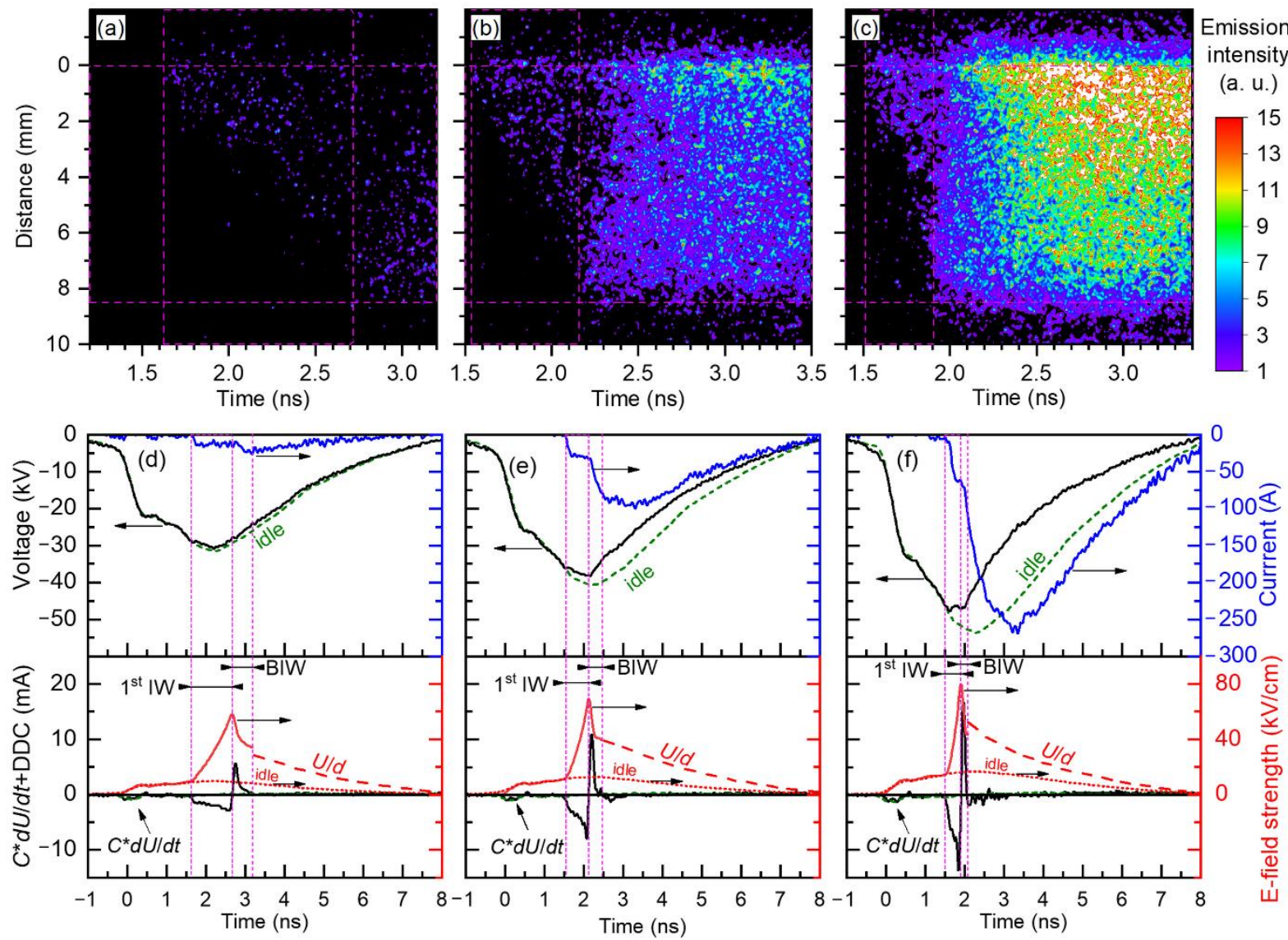

Figure 5. (a-c) Streak-images of the discharge formation dynamics and (d-f) corresponding waveforms of voltage, $U_{\text {gap }}$, current, $I_{\mathrm{d}}$, displacement current $\left(C_{\text {gap }} d U_{\text {gap }} / d t+\right.$ DDC) measured with the collector placed downstream the grounded grid electrode, and the electric field strength (calculated) near the surface of the grounded electrode at various voltages across the gap. 1st IW-first ionization wave (streamer), BIW-backward ionization wave. Air at a pressure of $100 \mathrm{kPa}$.

With increasing voltage across the gap, the rise time of the discharge current decreases significantly. However, at the highest voltage (Figure $5 \mathrm{c}, \mathrm{f}$ ), the discharge current continues to increase after the propagation of the backward ionization wave, despite a noticeable voltage drop. This indicates an increase in the conductivity of the discharge channel and the electron concentration in plasma.

After the backward ionization wave, the resistance of the discharge channel is quite large (more than $300 \mathrm{Ohms}$ ). In this case, the average electric field strength is $\approx 50 \mathrm{kV} / \mathrm{cm}$, 
which exceeds the breakdown threshold for air at a pressure of $100 \mathrm{kPa}(\approx 32 \mathrm{kV} / \mathrm{cm})$. Figure $5 \mathrm{c}$ shows that after the backward ionization wave has reached the pointed electrode, there is a slow propagation of the light front towards the grounded flat electrode (a third ionization wave). During this time, the discharge current reaches its maximum $(\approx 260 \mathrm{~A})$, and the resistance of the discharge channel reaches $\approx 90 \mathrm{Ohm}$ and does not decrease significantly until the end of the voltage pulse. The average electric field strength is $\approx 30 \mathrm{kV} / \mathrm{cm}$, when the resistance of the discharge channel reaches $\approx 90 \mathrm{Ohm}$. The absence of a significant change in the discharge channel resistance correlates with a decrease in the average electric field strength below the threshold value.

Estimates of the energy input into the discharge based on the data on voltage and current show that $\approx 10 \%$ of the total energy $(\approx 2 \mathrm{~mJ})$ was deposited during the propagation of the streamer and the backward ionization wave. Another $40 \%$ was deposited in the discharge during the propagation of the third ionization wave.

Figure 6 shows the dependence of the discharge formation dynamics on the pressure $(50,25,13 \mathrm{kPa})$ when applying voltage pulses with the highest amplitude $(27 \mathrm{kV})$. A decrease in the gas pressure leads to an increase in the reduced electric field strength and, accordingly, to an increase in the ionization wave velocities. After the passage of the streamer and the backward ionization wave, ionization of the gas in the gap continues. Furthermore, at an air pressure of 50,25, and $13 \mathrm{kPa}$, the discharge current tends to the short-circuit current, which may indicate the continuation of ionization processes in the gap despite a significant voltage drop. A decrease in pressure up to $13 \mathrm{kPa}$ has a greater effect on the third ionization wave than on the streamer and backward wave. As a result, the current rise time to a maximum is $\approx 300 \mathrm{ps}$.
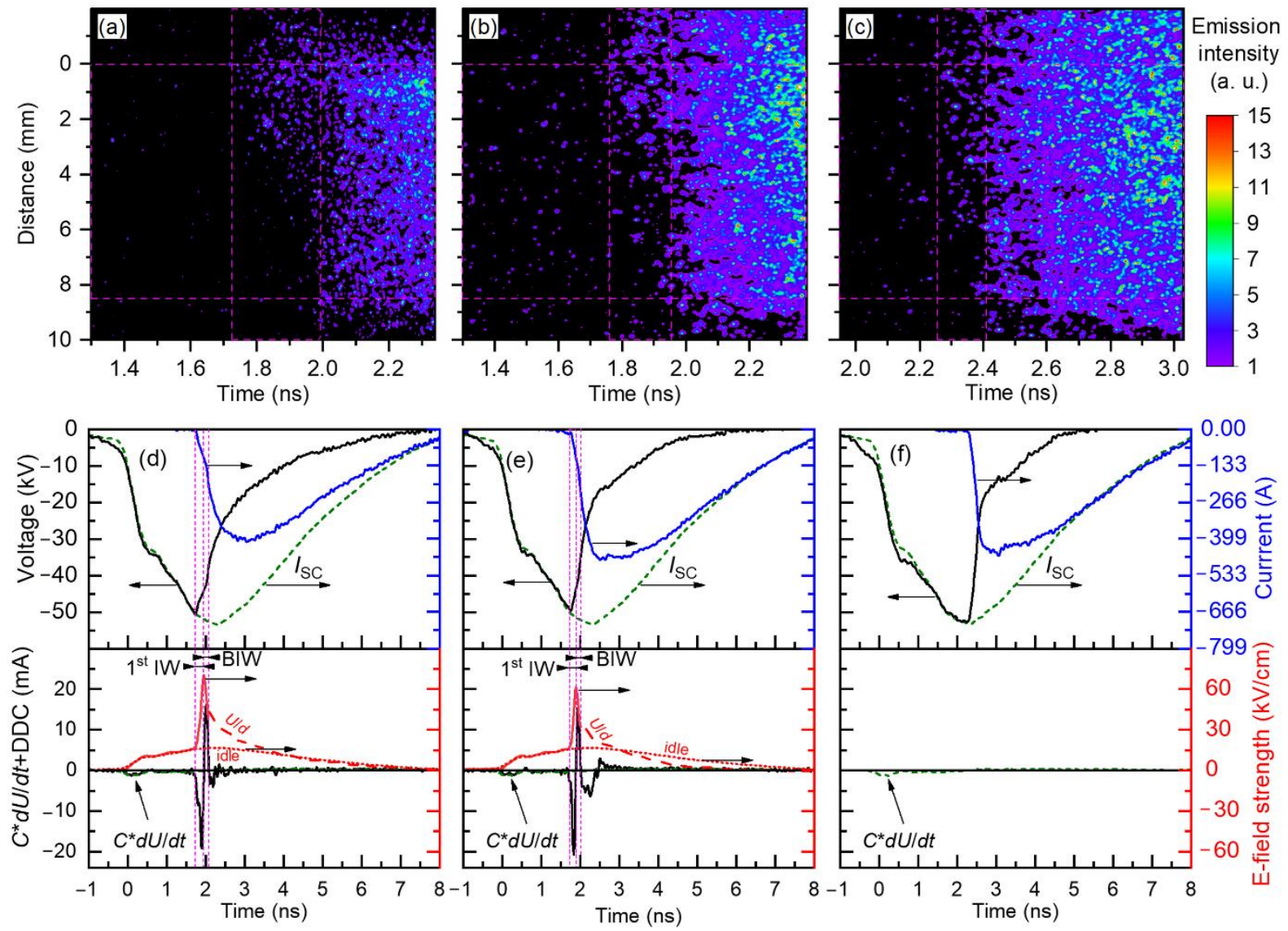

Figure 6. (a-c) Streak-images of the discharge formation dynamics and (d-f) corresponding waveforms of voltage, $U_{\text {gap }}$ current, $I_{\mathrm{d}}$, displacement current $\left(C_{\text {gap }} d U_{\text {gap }} / d t+\right.$ DDC) measured with the collector placed downstream the grounded grid electrode, and the electric field strength (calculated) near the surface of the grounded electrode at various air pressures. 1st IW-first ionization wave (streamer), BIW—-backward ionization wave. 
Note that, at an air pressure of $13 \mathrm{kPa}$, it was not possible to measure DDC due to the high amplitude of signals from the collector arising from repeated breakdowns by reflected voltage pulses.

\section{Conclusions}

The results of the studies performed show that significant pre-breakdown currents accompany the appearance and development of a streamer, as well as the subsequent propagation of a backward ionization wave in point-to-plane gaps. This is due to the fact that the appearance of the streamer with a large diameter (of the order of the gap length) in a point-to-plane gap changes its capacity by several times, and even by order. Because streamer formation begins in the vicinity of the pointed electrode, where the electric field is enhanced, the ionization rate is high. Accordingly, the rate of redistribution of the electric field, and hence the change in capacity, is also high. The rapidly varying electric field strength causes significant displacement currents and, accordingly, the flow of significant current in the external circuit. This leads to a drop in the voltage across the gap even before it is completely bridged by the plasma. By controlling the geometry of electrodes and overvoltage level, it is possible to achieve high rates of current rise.

Author Contributions: Methodology, D.B.; project administration, V.T.; writing—original draft, D.B.; writing - review and editing, D.S. and V.T. All authors have read and agreed to the published version of the manuscript.

Funding: This research was supported by the Ministry of Science and Higher Education of the Russian Federation within Agreement no. 075-15-2021-1026.

Data Availability Statement: Data is contained within the paper.

Acknowledgments: The authors are thankful to LLC Alfa Instruments for providing the Tektronix MSO64B oscilloscope.

Conflicts of Interest: The authors declare no conflict of interest. The funders had no role in the design of the study; in the collection, analyses, or interpretation of data; in the writing of the manuscript; or in the decision to publish the results.

\section{References}

1. Babaeva, N.Y.; Naidis, G.V. Universal nature and specific features of streamers in various dielectric media. J. Phys. D Appl. Phys. 2021, 54, 223002. [CrossRef]

2. $\quad$ Akishev, Y.S.; Balakirev, A.A.; Grushin, M.E.; Karalnik, V.B.; Medvedev, M.A.; Petryakov, A.V.; Trushkin, N.I. Pin-to-plane self-pulsing discharge in transversal airflow: Interaction with a substrate of plasma filaments blown out from the discharge zone. Plasma Sources Sci. Technol. 2020, 29, 045012. [CrossRef]

3. Bourdon, A.; Péchereau, F.; Tholin, F.; Bonaventura, Z. Study of the electric field in a diffuse nanosecond positive ionization wave generated in a pin-to-plane geometry in atmospheric pressure air. J. Phys. D Appl. Phys. 2021, 54, 075204. [CrossRef]

4. Paulauskas, R.; Jogi, I.; Striugas, N.; Martuzevičius, D.; Erme, K.; Raud, J.; Tichonovas, M. Application of non-thermal plasma for NOx reduction in the flue gases. Energies 2019, 12, 3955. [CrossRef]

5. Zhu, Y.; Chen, X.; Wu, Y.; Hao, J.; Ma, X.; Lu, P.; Tardiveau, P. Simulation of ionization-wave discharges: A direct comparison between the fluid model and E-FISH measurements. Plasma Sources Sci. Technol. 2021, 30, 075025. [CrossRef]

6. Wang, D.; Namihira, T. Nanosecond pulsed streamer discharges: II. Physics, discharge characterization and plasma processing. Plasma Sources Sci. Technol. 2020, 29, 023001. [CrossRef]

7. Liu, C.; Fridman, A.; Dobrynin, D. Investigation of the transition from streamer to uniform overvoltage mode of atmospheric air nanosecond-pulsed dielectric barrier discharge. J. Phys. D Appl. Phys. 2019, 52, 105205. [CrossRef]

8. Brisset, A.; Tardiveau, P.; Gazeli, K.; Bournonville, B.; Jeanney, P.; Ouaras, K.; Magne, L.; Pasquiers, S. Experimental study of the effect of water vapor on dynamics of a high electric field non-equilibrium diffuse discharge in air. J. Phys. D Appl. Phys. 2021, 54, 215204. [CrossRef]

9. Guo, X.; Hu, E.; Li, X.; Yin, G.; Huang, Z. Experimental study on ignition characteristics of RP-3 jet fuel using nanosecond pulsed plasma discharge. Energies 2021, 14, 6463. [CrossRef]

10. Kozlov, B.; Makhan'ko, D.; Seredinov, V. A new design of high-voltage pulse generators for ignition of volume discharges at super-atmospheric pressures in a pulse-periodical regime. In Proceedings of the 2020 7th International Congress on Energy Fluxes and Radiation Effects (EFRE), Tomsk, Russia, 14-26 September 2020.

11. Chu, P.K.; Lu, X. (Eds.) Low Temperature Plasma Technology; CRC Press: Boca Raton, FL, USA, 2014; 481p. 
12. Weltmann, K.-D.; Kolb, J.F.; Holub, M.; Uhrlandt, D.; Šimek, M.; Ostrikov, K.; Hamaguchi, S.; Cvelbar, U.; Černák, M.; Locke, B.; et al. The future for plasma science and technology. Plasma Process. Polym. 2018, 16, 1800118. [CrossRef]

13. Korolev, Y.D.; Mesyats, G.A. Physics of Pulsed Breakdown in Gases; URO-Press: Yekaterinburg, Russia, 1998; 274p.

14. Sorokin, D.A.; Tarasenko, V.F.; Beloplotov, D.V.; Lomaev, M.I. Features of streamer formation in a sharply non-uniform electric field. J. Appl. Phys. 2019, 125, 143301. [CrossRef]

15. Belomyttsev, S.Y.; Grishkov, A.A.; Shklyaev, V.A.; Ryzhov, V.V. Current in a pulsed gas breakdown at a highly inhomogeneous electric field. J. Appl. Phys. 2018, 123, 043309. [CrossRef]

16. Belomyttsev, S.Y.; Grishkov, A.A.; Shklyaev, V.A.; Ryzhov, V.V. Effect of the ionization wave velocity on the current and voltage of a gas-filled diode. J. Appl. Phys. 2018, 123, 203302. [CrossRef]

17. Shao, T.; Tarasenko, V.F.; Zhang, C.; Burachenko, A.G.; Rybka, D.V.; Kostyrya, I.D.; Lomaev, M.I.; Baksht, E.K.; Yan, P. Application of dynamic displacement current for diagnostics of subnanosecond breakdowns in an inhomogeneous electric field. Rev. Sci. Instrum. 2013, 84, 053506. [PubMed]

18. Beloplotov, D.V.; Lomaev, M.I.; Sorokin, D.A.; Tarasenko, V.F. Measurement of the Dynamic Displacement Current as a New Method of Study of the Dynamics of Formation of a Streamer at a Breakdown of Gases at a High Pressure. JETP Lett. 2018, 107, 606-611. [CrossRef]

19. Tarasenko, V.F.; Rybka, D.V.; Balzovsky, E.V. Techniques and detectors for measurement of subnanosecond and picosecond pulses of electron beam current, current through the discharge gap and voltage. In Generation of Runaway Electron Beams and X-rays in High Pressure Gases, Volume 1: Techniques and Measurements; Tarasenko, V.F., Ed.; Nova Science Publishers, Inc.: New York, NY, USA, 2016; Chapter 7, pp. 129-155.

20. Tarasenko, V.F.; Rybka, D.V. Methods for recording the time profile of single ultrashort pulses of electron beams and discharge currents in real-time mode. High Volt. 2016, 1, 43-51. [CrossRef]

21. Efanov, V.M.; Efanov, M.V.; Komashko, A.V.; Kirilenko, A.V.; Yarin, P.M.; Zazoulin, S.V. High-Voltage and High-PRF FID Pulse Generators. In Ultra-Wideband, Short Pulse Electromagnetics 9; Sabath, F., Giri, D.V., Rachidi-Haeri, F., Kaelin, A., Eds.; Springer: New York, NY, USA, 2010; Part 5, pp. 301-305.

22. Beloplotov, D.V.; Tarasenko, V.F.; Shklyaev, V.A.; Sorokin, D.A. Generation of runaway electrons in plasma after a breakdown of a gap with a sharply non-uniform electric field strength distribution. J. Phys. D Appl. Phys. 2021, 54, 304001. [CrossRef] 